\section{Response of Plant Growth and Development, and Accumulation of Hydroxyl-cinnamoyl Acid Derivatives to Selected Shade Nets and Seasonality of Field-grown Bush Tea (Athrixia phylicoides DC.)}

\author{
Maanea L. Ramphinwa \\ Department of Agriculture and Animal Health, College of Agriculture \\ and Environmental Sciences, University of South Africa, Private Bag X6, \\ Florida, 1710, South Africa; and Department of Plant and Soil Sciences, \\ Faculty of Science, Engineering and Agriculture, University of Venda, \\ Private Bag X5050, Thohoyandou, 0950, South Africa \\ Godwin R.A. Mchau \\ Department of Plant and Soil Sciences, Faculty of Science, Engineering \\ and Agriculture, University of Venda, Private Bag X5050, Thohoyandou, \\ 0950, South Africa
}

Ntakadzeni E. Madala and Ndamulelo Nengovhela

Department of Biochemistry and Microbiology, Faculty of Science, Engineering and Agriculture, University of Venda, Private Bag X5050, Thohoyandou, 0950, South Africa

John B.O. Ogola

Department of Plant and Soil Sciences, Faculty of Science, Engineering and Agriculture, University of Venda, Private Bag X5050, Thohoyandou, 0950, South Africa

\section{Fhatuwani N. Mudau}

Department of Agriculture and Animal Health, College of Agriculture and Environmental Sciences, University of South Africa, Private Bag X6, Florida, 1710, South Africa; and School of Agricultural, Earth and Environmental Sciences, University of Kwa-Zulu Natal, Cabbis Road, Scottsville, Pietermaritzburg, 3209

Additional index words. herbal tea, quality control, protected environment, light intensity, quality index

\begin{abstract}
Horticultural practices and quality of bush tea (Athrixia phylicoides DC.) are critical for herbal tea industrialization. The objective of the current study was to determine the effect of selected shade nets and seasonal variation on plant growth and development, and hydroxycinnamic acid content of field-grown bush tea. The trial was laid out in a randomized complete block design consisting of three shade nets (black, green, and white) and control or full sunlight with three different light intensities $(40 \%, 50 \%$, and $80 \%)$ replicated three times. Proportion of intercepted radiation by the canopy, chlorophyll content, plant height, and fresh and dry mass were measured, and hydroxycinnamic acid accumulation was determined. In addition, hydroxycinnamic acid composition was determined using liquid chromatography linked to mass spectrometry (LC-MS). The application of shade nets resulted in plant growth and yield reduction as compared with the plants exposed to full sunlight during summer followed by white shade net. The accumulation of hydroxycinnamic acid was higher in $\mathbf{8 0} \%$ white shade net plots compared with unshaded plants (control) and the other shade nets. Therefore, lack of shading provides a conducive environment to enhance plant growth and development of bush tea. The white shade net $(80 \%)$ was an effective microclimate tool to enhance accumulation of caffeoylquinic acid (m/z 353), p-coumaric acids (m/z 337), dicaffeoylquinic acid (m/z 515), and tricaffeoylquinic acids of bush tea. This study is the first to demonstrate light as a determining factor for production of chlorogenates in bush tea plants. Future studies will be conducted to determine the effect of light on extracts of the bush tea using different solvents.
\end{abstract}

Bush tea (A. phylicoides DC.) is a native plant of South Africa and it grows naturally in different climatic conditions of South Africa (Mavundza et al., 2010; Nchabeleng et al., 2012; Van Wyk and Gericke, 2000). The plant grows to a height of $\approx 0.5 \mathrm{~m}$ to 1 $\mathrm{m}$, with branches of thin woolly stems (Mudau et al., 2006). It has simple alternate leaves that are described as linear, light graygreen above, and white-woolly below (Mudau et al., 2006). The leaf bases are broadly lanceolate, short stalked, taper to a sharp point, auriculate, smooth on the upper surface, and have margins that are entirely or slightly revolute (Mudau et al., 2006). The head of the inflorescence is sessile or subsessile with terminal axillary in large sub corymbose panicles (Herman et al., 2000).

It is used traditionally as an important herbal and medicinal plant by South Africans to cleanse and purify blood, treat boils, heal wounds, and treat headaches (Fouché et al., 2006; Mudau et al., 2007). In some parts of the country, it is used as an aphrodisiac (Rakuambo, 2011). To date, bush tea is still harvested from the wild for a variety of medicinal purposes (e.g., to treat chronic diseases such as cardiovascular disease and cancer) and hence there is a huge potential for development of $A$. phylicoides as a commercial health benefit herb in South Africa (Mudau et al., 2006). Therefore, domestication of bush tea is critical for commercial exploitation to protect the species from possible extinction.

Previous studies have documented the effects of cultural practices such as mineral nutrition (Mudau et al., 2006), pruning (Mohale et al., 2018; Yilmaz et al., 2004), irrigation (Bandara, 2012) and harvesting methods (Mphangwe, 2012), as well as processing (Hlahla, 2010) and environmental conditions (Tshivhandekano et al., 2013) on chemical compositions of bush tea. The quality, economic value, and health function of bush tea is determined by the content of secondary metabolites such as flavonoids (or phenolic compounds), alkaloids, and amino acids (Tounekti et al., 2013). Zhang et al. (2014) reported that quality parameters of tea are significantly affected by environmental factors and management practices. Application of nitrogen $(\mathrm{N})$ fertilizer increases total phenol concentrations in cultivated medicinal plants by enhancing photosynthetic rate (Haukioja et al., 1998) and accumulation of nonstructural carbohydrates (Wanyoka, 1983).

However, it has been reported that carbonbased secondary metabolites increase frequently when environmental conditions enhance the accumulation of nonstructural carbohydrates in Labisia pumila plants (Ibrahim et al., 2011). Hydroxycinnamic acids (coumaric acid, ferulic acid, sinapic acid, and caffeic acid) are phenolic compounds that are found in plants either as free compounds or conjugated to other molecules such as quinic acid, tartaric acid, citric acid, and sugars (Ncube et al., 2014). These derivatives are known as chlorogenic acids (CGAs) when they are conjugated/esterified to 
A

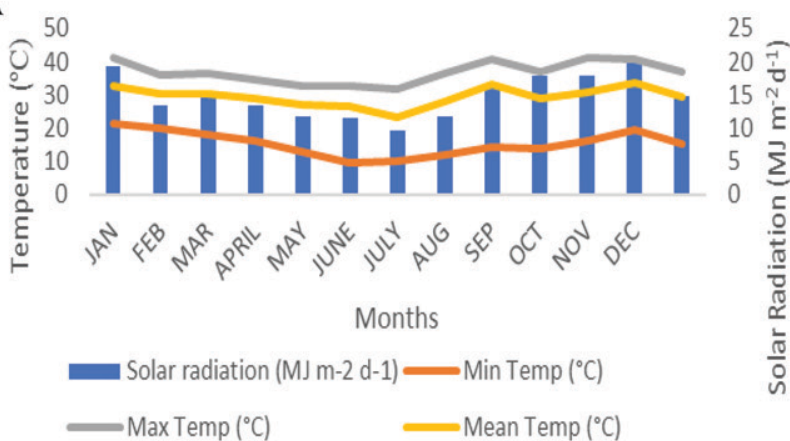

C

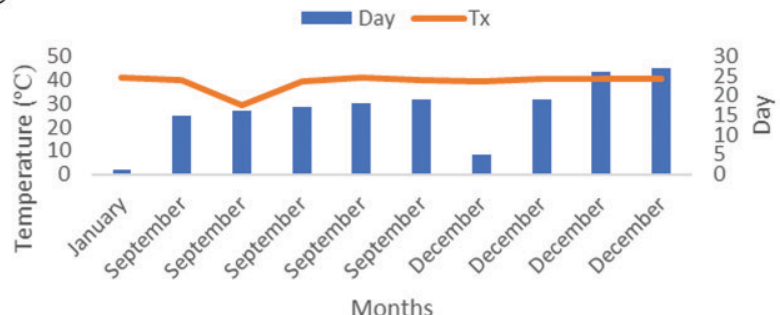

B

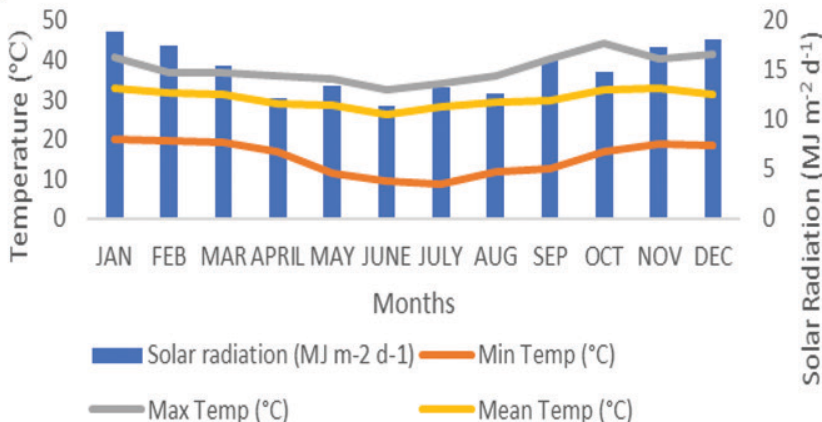

D

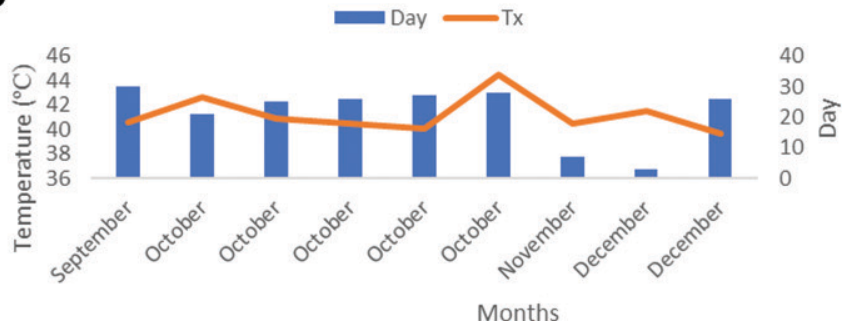

Fig. 1. (A) Data denoting minimum and maximum temperatures during 2018. (B) Data denoting minimum and maximum temperatures in 2019. (C) Data denoting temperature $>40^{\circ} \mathrm{C}$ in 2018 . (D) Data denoting temperature $>40^{\circ} \mathrm{C}$ in 2019 . Tx, maximum temperature.

other molecules (Masike et al., 2017; Nobela et al., 2018; Roleira et al., 2018). CGAs are classified into two groups: mono- and dicaffeoylquinic acids (CQAs) (Ncube et al., 2014). Plants naturally produce and use CGAs to aid their protection against abiotic (Lallemand et al., 2012; Taofiq, et al., 2017) and biotic (Ramabulana et al., 2020) stresses, as they have been reported to be effective defense phytochemicals (Kundu and Vadassery, 2019). Several hydroxyl-cinnamic acid derivatives such as 3,5-dicaffeoylquinic acid (3,5-diCQA) have been shown to have anti-HIV-1 INT enzyme activity that is attributed to trans-cis isomerization (Masike et al., 2017).

Net shades improve the quality of tea leaves due to an increase in the concentration of amino acids with lower content of catechin in the plant (Ku et al., 2010) and it also prevents the concentration of flavonoids (Wang et al., 2012). Net shade has also been reported to provide $50 \%$ to $70 \%$ of diffused solar insolation to the tea cultivation area (Lehlohonolo et al., 2013). Shade netting has been used in normal tea plantation in major tea producing areas to enhance optimum growth and productivity (Janendra et al., 2007). In green tea production, the ratio of oxalate content to reduced $\mathrm{N}$ content was higher in the flushes exposed to shading environment than the flushes under full sunlight (Morita and Tuji,

Received for publication 2 Aug. 2021. Accepted for publication 1 Oct. 2021.

Published online 17 December 2021.

F.M.N. is the corresponding author. E-mail: mudauf@ukzn.ac.za.

This is an open access article distributed under the CC BY-NC-ND license (https://creativecommons. org/licenses/by-nc-nd/4.0/).
2002). Although several studies have documented plant growth and yield, as well as the quality response of bush tea to shade nets, most research has been conducted in pot experiments under controlled environments (de Beer et al., 2011; Mavundza et al., 2010; Mudau et al., 2007; Tshivhandekano et al., 2014). Moreover, information that describes the accumulation of hydroxycinnamic acids (HCAs) in bush tea grown in the field under different shade nets, as a standard agricultural horticultural practice to create conducive microclimate due to climate change, is still lacking. Therefore, the objective of the current study was to determine the effect of selected shade nets and seasons on plant growth and development, and hydroxycinnamic acid accumulation of field-grown bush tea.

\section{Materials and Methods}

Experimental site. The field trial was established in Autumn 2018 at the University of Venda's experimental farm, which is situated at Thohoyandou (lat. $22^{\circ} 58.081^{\prime} \mathrm{S}$, long. $30^{\circ} 26.411^{\prime} \mathrm{E}$, and $595 \mathrm{~m}$ asl), Limpopo Province, South Africa. The site is characterized by an annual rainfall of $\approx 500 \mathrm{~mm}$ that falls mainly in summer, and average maximum and minimum temperature of $31^{\circ} \mathrm{C}$ and $18^{\circ} \mathrm{C}$, respectively (Tadross et al., 2006). The type of the soils at the experimental site are characterized by deep, well-drained clays with slightly acidic $\mathrm{pH}$ (Soil Classification Working Group, 1991). Weather data were supplied by South African weather service for 2018 and 2019 cropping seasons.
Annual and seasonal weather pattern during 2018 and 2019. Thohoyandou had high maximum and minimum average temperatures throughout the year. Monthly average maximum and minimum temperatures ranged from 30 to $40^{\circ} \mathrm{C}$ and 10 to $20^{\circ} \mathrm{C}$, respectively, in both years (Fig. 1A and B). Temperature $>40^{\circ} \mathrm{C}$ was recorded in Dec. 2018 and Sept. and Oct. 2019 (Fig. 1C and D). Rainfall distribution was very poor with hardly any rainfall being recorded between May and October in both years (Fig. 2).

Preparations of stem cuttings. The wild bush tea stem cuttings were collected from Tshivhulani Village (lat. $22^{\circ} 55.331 ' \mathrm{~S}$, long. $30^{\circ} 18.218^{\prime} \mathrm{E}$, altitude $610 \mathrm{~m}$ ), which is characterized by cold and dry winters. Planting materials of apical cuttings were cut at $\approx 7$ to $8 \mathrm{~cm}$ long and dipped in Seradix No. 2 hormone $(0.3 \%$ IBA) to stimulate rapid and prolific rooting. "True-to-name and type" material that was free of disease and insect damage was selected for planting. Stem cuttings were established on a $25-\mathrm{cm}$-round plastic pot in a lath house at the University of Venda on 25 Oct. 2017. Plants were irrigated daily except on rainy days. Rooted cuttings were transplanted into $1-\mathrm{L}$ bags and placed into a net shade on 7 Dec. 2017 for a period of 3 months. Planting materials, with $\approx 25$ leaves, were transplanted into four different types of environmental conditions (i.e., control, black, white, and green shade nets) on 12 Mar. 2018. Data collection commenced 3 months after transplanting when the plants were well established. Growth/rooting media was a mixture of pine bark and sand at a ratio of $2: 1$. The initial media test chemical analyses were determined using Hanlon et al. (1994) procedure. The nitrogen-phosphorous-potassium $(\mathrm{N}-\mathrm{P}-\mathrm{K})$ fertilizer was applied in two 


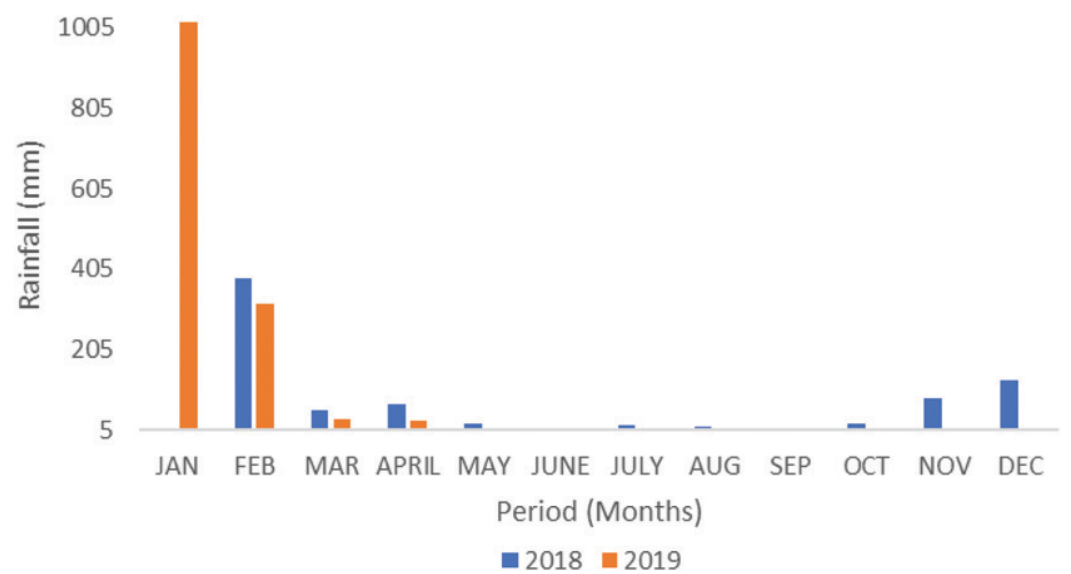

Fig. 2. The pattern of rainfall of Thohoyandou, South Africa, Limpopo Province during 2018 and 2019.

equal splits (at transplanting and 2 weeks after transplanting) at a rate $300 \mathrm{~kg} \cdot \mathrm{ha}^{-1} \mathrm{~N}, 300$ $\mathrm{kg} \cdot \mathrm{ha}^{-1} \mathrm{P}$, and $200 \mathrm{~kg} \cdot \mathrm{ha}^{-1} \mathrm{~K}$ based on previous studies (Mudau et al., 2007).

Experimental description. The experiment was laid out in a randomized complete block design consisting of three shade nets (black, green, and white) and full sunlight with three different light intensities $(40 \%, 50 \%$, and $80 \%)$ replicated three times. The size of the individual plots was $4.8 \mathrm{~m} \times 4.8 \mathrm{~m}$. Each plot consisted of four plant rows, $1.2 \mathrm{~m}$ apart and the intrarow spacing was $0.75 \mathrm{~m}$, giving a total of 24 plants per plot. The plots were watered, using a drip irrigation system, when necessary. Weeding was done manually throughout the cropping season to keep the experimental plots weed-free. Methamidophos was applied at a rate of $10 \mathrm{~mL}$ per $20 \mathrm{~L}$ after each weeding occasion to protect the plants against termites.

Growth parameters. Bush tea is a perennial crop that flowers throughout the year and is able to resprout after being cut. Data were collected only from regenerated plants for each season. Pruning was done after each harvest to avoid mineral resource competition between the previous and regenerated plants. In 2018, data collection began on 12 June for the winter season. Each net plot had four rows excluding the guard rows. Sixteen plants from the second inner rows of each experimental plot were harvested once per season. Plant height (from the soil surface to the tip of the topmost leaf) was determined a day before each harvest using a measuring tape. Fresh weight was recorded after harvest in each season each year using a weighing balance. The harvested plants were air-dried, under room temperature, for 2 months. The proportion of dry matter content was obtained by expressing the dry weight as a percentage of the fresh weight of the sample taken as shown in Eq. 1.

$$
\text { Dry matter }(\%)=\frac{\text { Dry weight }}{\text { Fresh weight }} \times 100
$$

Chlorophyll content. Leaf chlorophyll content was determined, between 0900 and $1200 \mathrm{HR}$ on each occasion, from five plants in each plot using chlorophyll content meter
(CCM-200 Plus; Opti-Sciences, Tyngsboro, MA). Measurements were taken weekly between 26 and 33 weeks (Winter 2018), 38 and 46 weeks (Spring 2018), 49 and 62 weeks (Summer 2018), 71 and 73 weeks (Autumn 2019) and 78 and 87 weeks (Winter 2019), 90 and 98 weeks (Spring 2019), 102 and 112 weeks (Summer 2019), and 118 and 120 weeks (Autumn 2020).

Proportion of intercepted radiation by the canopy cover. Photosynthetically active radiation $(P A R)$ measurements were taken at 7day intervals, and the dates cover the vegetative and reproductive stages of plant growth in each season. The proportion of intercepted radiation was determined by measuring $P A R$ above and below the canopy on various occasions, mostly at 7-day intervals, between 26 and 33 weeks (Winter 2018), 38 and 46 weeks (Spring 2018), 49 and 62 weeks (Summer 2018) and 71 and 73 weeks (Autumn, 2019) and 78 and 87 weeks (Winter 2019), 90 and 98 weeks (Spring 2019), 102 and 112 weeks (Summer 2019), and 118 and 120 weeks (Autumn, 2020). The measurements were taken between 1100 and $1300 \mathrm{HR}$ on clear, cloudless days using an AccuPar LP-80 Ceptometer and the proportion of intercepted radiation $(\alpha)$ was calculated as shown in Eq. 2.

$$
\alpha=1-\left(\mathrm{P}_{\mathrm{A}} / \mathrm{P}_{\mathrm{B}}\right)
$$

where $\mathrm{P}_{\mathrm{A}}$ is the $P A R$ above the canopy; $\mathrm{P}_{\mathrm{B}}$ is the PAR below the canopy; and $\alpha$ is the proportion of the intercepted radiation.

Metabolites extraction. Metabolite extraction was accomplished by a method proposed by Makita et al. (2016). In brief, bush tea leaves were manually threshed from dried plants and ground as soon as the dry mass was weighed for the autumn season. They were ground to fine powder using a hammer grinder, and $2 \mathrm{~g}$ of fine ground leaves was mixed with $20 \mathrm{~mL}(1: 10 \mathrm{~m} / \mathrm{v})$ of $80 \%$ aqueous methanol. The homogenate was centrifuged at $5000 \mathrm{~g}_{\mathrm{n}}$ for $20 \mathrm{~min}$ to remove debris, and finally, the supernatant was transferred to new clean tubes. The extracts were further diluted 1:1 (v:v) to final volume of $20 \mathrm{~mL}$ using methanol, followed by transfer of 10 $\mathrm{mL}$ of the diluted extracts into cylindrical quartz glass vials $(2 \times 10 \mathrm{~cm})$. The samples were filtered into a $2-\mathrm{mL}$ vial fitted with a $0.2-\mathrm{mL}$ conical bottom glass insert using a syringe fitted with a $0.2-\mu \mathrm{mm}$ filter

LC-MS analysis. Bush tea sample analysis was conducted on an $\mathrm{LC}$-quadrupole time of flight (QTOF)-MS, model LC-MS 9030 instrument with a Shim Pack Velox C18 column $(100 \mathrm{~mm} \times 2.1 \mathrm{~mm}$ with particle size of $2.7 \mu \mathrm{m}$ ) (Shimadzu, Kyoto, Japan), placed in a column oven set at $40^{\circ} \mathrm{C}$. A binary solvent mixture, consisting of $0.1 \%$ formic acid in water (Eluent $\mathrm{A}$ ) and $0.1 \%$ formic acid in acetonitrile (Eluent B) was used at a constant flow rate of $0.4 \mathrm{~mL} / \mathrm{min}$. A mass spectrometer detector was used for monitoring analyte elations, under the following conditions: ESI (electrospray ionization) negative modes; interface voltage of $3.5 \mathrm{kV}$; nitrogen gas was used as nebulizer at flow rate $3 \mathrm{~L} / \mathrm{min}$, heating gas flow at $10 \mathrm{~L} / \mathrm{min}$; heat block temperature at $400^{\circ} \mathrm{C}$, $\mathrm{CDL}$ temperature at $250^{\circ} \mathrm{C}$; detector voltage of $1.70 \mathrm{kV}$ and the TOF temperature at $42^{\circ} \mathrm{C}$.

Tandem MS experiments. For tandem MS (MSMS) experiments, a mass calibration solution of sodium iodide (NaI) was used to obtain typical mass accuracies with a mass error below $1 \mathrm{ppm}$, and a range of $\mathrm{m} / \mathrm{z} 100$ to 1000 was used for high resolution. Argon gas was used as a collision gas for MSMS experiments along with $\mathrm{MS}^{\mathrm{E}}$ mode using collision energy ramp of $12 \mathrm{eV}$ to $25 \mathrm{eV}$ for generation of fragments.

Statistical analysis. All plant growth data were subjected to analysis of variance using SPSS version 27 (IBM Corp., Armonk, NY). Means were separated using the Duncan's multiple range test when the F-test indicated significant differences among the treatments. Correlation analysis was conducted to assess the relationships between the physiological parameters.

\section{Results and Discussion}

Proportion of intercepted radiation. Shade nets and seasons affected $(P \leq 0.001)$ the proportion of intercepted radiation by the crop canopy at all measurement dates in both 2018 and 2019 (Figs. 3 and 4). On average, the proportion of intercepted radiation was higher in control (57.8\%) compared with white color $(57.2 \%)$, green shade $(50.2 \%)$, and black shade $(52.4 \%)$ (Table 1$)$. The higher proportion of intercepted radiation observed in control compared with other treatments could be attributed to the larger canopy size and plant height of the plants that were exposed to full sunlight (Muchow et al., 1990). Our findings are comparable to earlier observations that different shade nets can influence microclimatic parameters that control plant growth and development (Kumar et al., 2013).

Total intercepted radiation. Control had significantly $(P \leq 0.001)$ higher total intercepted radiation than the other treatments in both years (Figs. 5 and 6), which is consistent with earlier findings that black shade nets tended to absorb more light compared with other shade nets (Mokoka, 2007). These findings are consistent with those of Anwar et al. 
Table 1. Response of plant growth and development of bush tea cultivated under different shade nets color, light intensity, and season.

\begin{tabular}{|c|c|c|c|c|c|c|}
\hline & Source of variation & IR $(\%)$ & Plant ht (m) & Fresh wt (g/plant) & Dry mass (g/plant) & Chlorophyll content (nm) \\
\hline \multirow[t]{2}{*}{$\overline{\text { Color }}$} & Control & $57.8 \mathrm{a}$ & $159.8 \mathrm{a}$ & $762.1 \mathrm{a}$ & $382.5 \mathrm{a}$ & $16.1 \mathrm{a}$ \\
\hline & Green & $50.2 \mathrm{~b}$ & $147.6 \mathrm{a}$ & $402.3 \mathrm{c}$ & $240.6 \mathrm{~b}$ & $14.4 \mathrm{a}$ \\
\hline \multirow{3}{*}{ Light intensity (\%) } & 40 & $56.9 \mathrm{a}$ & $152.5 \mathrm{ab}$ & $499.8 \mathrm{~b}$ & $288.1 \mathrm{~b}$ & $14.8 \mathrm{a}$ \\
\hline & 50 & $55.2 \mathrm{a}$ & $157.2 \mathrm{ab}$ & $465.6 \mathrm{~b}$ & $230.9 \mathrm{bc}$ & $11.9 \mathrm{a}$ \\
\hline & 80 & $47.6 \mathrm{~b}$ & $144.2 \mathrm{c}$ & $362.4 \mathrm{c}$ & $180.7 \mathrm{c}$ & $14.7 \mathrm{a}$ \\
\hline \multirow{2}{*}{ Season } & Summer & $64.6 \mathrm{a}$ & $173.4 \mathrm{~b}$ & $636 \mathrm{a}$ & $314.5 \mathrm{a}$ & $11.4 \mathrm{a}$ \\
\hline & Winter & $58.7 \mathrm{~b}$ & $143.9 \mathrm{c}$ & $343.6 \mathrm{c}$ & $216.9 \mathrm{c}$ & $17.1 \mathrm{~b}$ \\
\hline
\end{tabular}

Means within a column followed by the same letter indicate no significant difference. Means within a column followed by different letter indicate significant difference.

(2003), who found that total intercepted radiation varies between treatments due to differences in days to physiological maturity. The interaction of shade nets and season also had a significant $(P \leq 0.001)$ effect on total intercepted radiation in all the seasons.

The effect of shade nets on plant growth and development of bush tea. There was a significant difference among plant growth parameters (proportion of intercepted radiation, fresh weight, and dry mass) on bush tea plants grown under different shade nets. However, chlorophyll content and plant height did not vary with shade nets (Table 1).

Fresh and dry mass. Plants from unshaded plots recorded the highest fresh biomass (762.1 g/plant) followed by white shade net treatments $(533.6 \mathrm{~g} / \mathrm{plant})$, with the lowest fresh biomass (391.9 g/plant) being recorded in plants grown under black shade nets (Table 1). The complex interaction between quantity and quality of incident radiation determines the response of plant to shading conditions (Lee et al., 1997). The significant decrease of fresh weight on plants grown under black shade net might be due to insufficient light the plants had received, which resulted in stunting growth that clearly demonstrates the importance of a favorable environment in determining plant growth and yield of bush tea in any region. Our results concur with earlier observations (Bell et al., 2000; Rao and Mittra, 1998) that tea grown under shade nets had an ability to reduce $P A R$, change spectral quality, and affect plant photosynthesis, dry matter production, and yield of the crop. Similarly, Marchese and Figueira (2005) reported that plant growth and development was significantly influenced by environmental factors such as radiation, temperature, and photoperiod, and that increased biomass and essential oil was associated with higher photosynthetic rate of plants and higher radiation. Although plants exposed to low light intensity at the vegetative stage tend to increase their capacity to trap light by increasing the leaf area, this did not significantly contribute toward biomass accumulation in our study. Similar results were reported by Mokoka (2007), who observed that $55 \%$ black shade nets significantly reduced fresh shoot mass relative to plants grown under $18 \%$ white shade nets in fever tea, which is in line with reports that yield reduction due to shading was determined by crop species and degree of shading (Kumar et al., 2013).

Effect of light intensity on plant growth and development of bush tea. There was a significant difference in plant growth parameters (i.e., intercepted radiation, plant height, fresh weight, and dry weight) of bush tea plants grown under different light intensities of
A

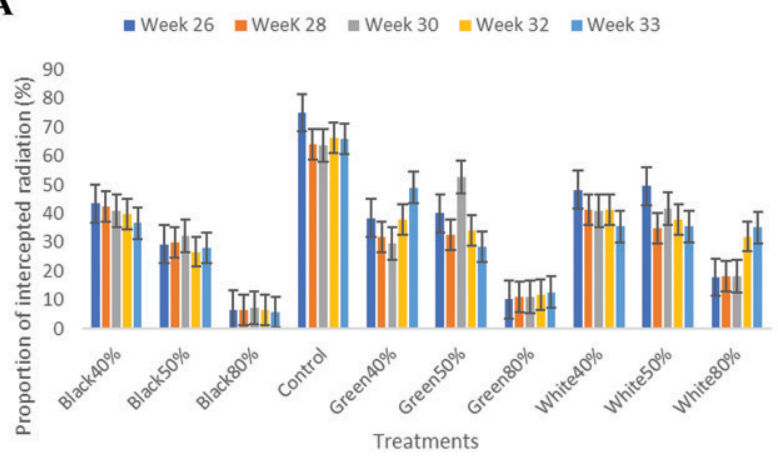

C

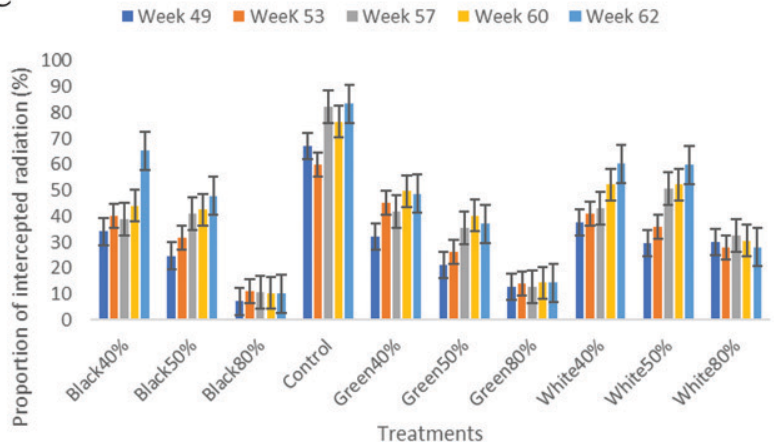

B

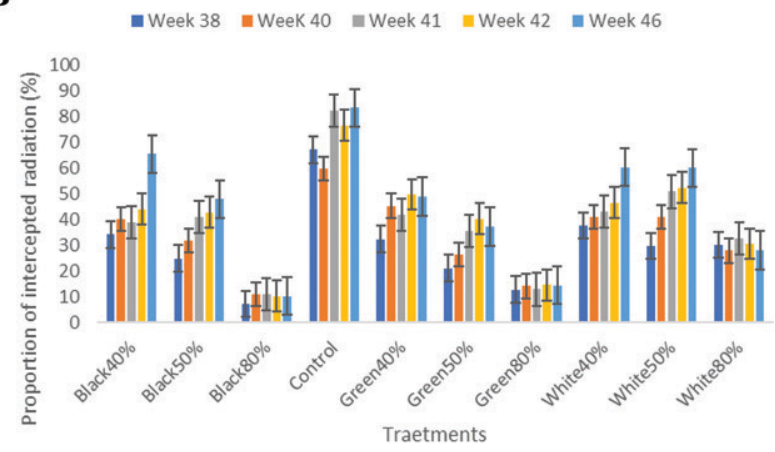

D

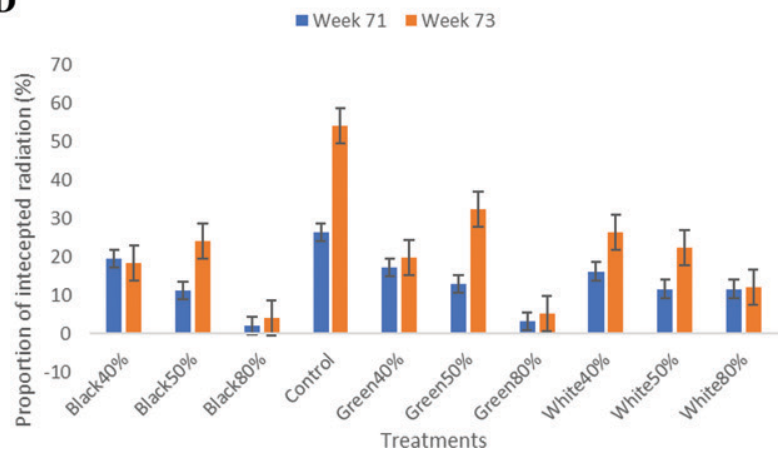

Fig. 3. The effect of treatments on the proportion of intercepted radiation in 2018. (A) Winter 2018. (B) Spring 2018. (C) Summer 2018. (D) Autumn 2019. 
A

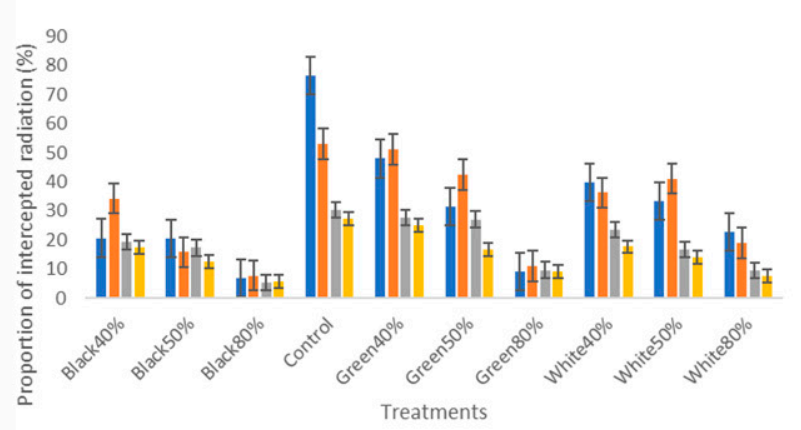

C

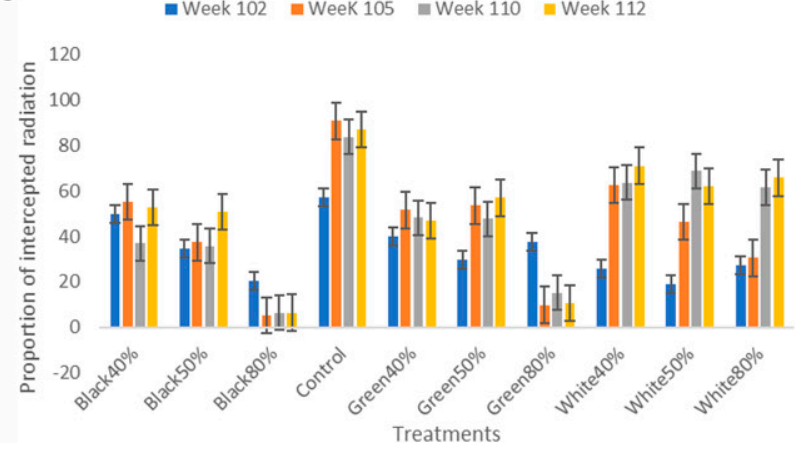

B

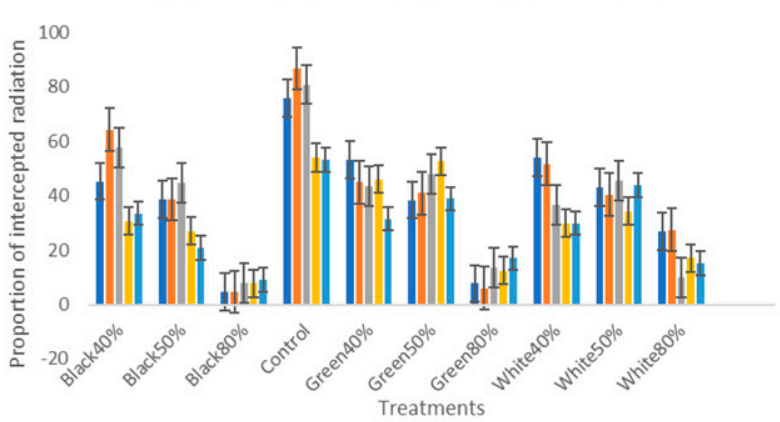

D

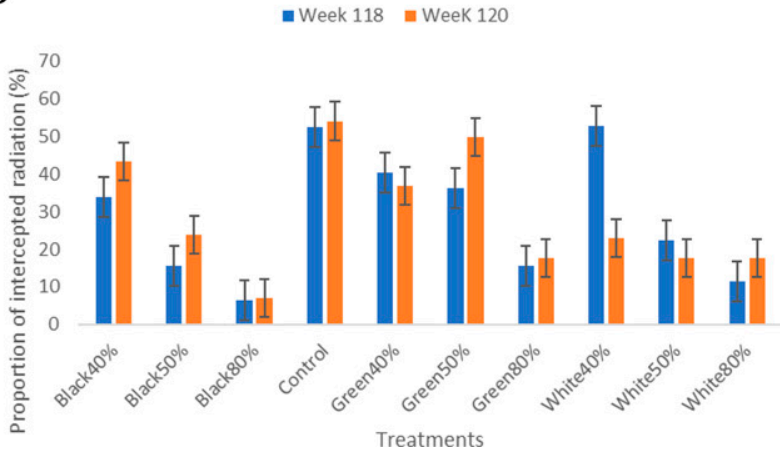

Fig. 4. The effect of treatments on the proportion of intercepted radiation in 2019. (A) Winter 2019. (B) Spring 2019. (C) Summer 2019. (D) Autumn 2020.

shade nets. However, light intensity did not affect chlorophyll content (Table 1).

The unshaded control exhibited the highest proportion of intercepted radiation $(57.7 \%)$, with the lowest $(47.6 \%)$ being recorded in $80 \%$ shade net plots
(Table 1). The response of plant height and fresh biomass to light intensity followed a similar trend, with the highest $(158 \mathrm{~m}$ and $772.3 \mathrm{~g} / \mathrm{plant})$ and lowest (144.2 $\mathrm{m}$ and $362.4 \mathrm{~g} /$ plant) plant height and fresh biomass recorded in unshaded control and $80 \%$ shade net plots, respectively (Table 1). The results of the current study are consistent with previous reports that changes in microclimate caused by spacing and shade levels result in significant differences in growth and development, with
A

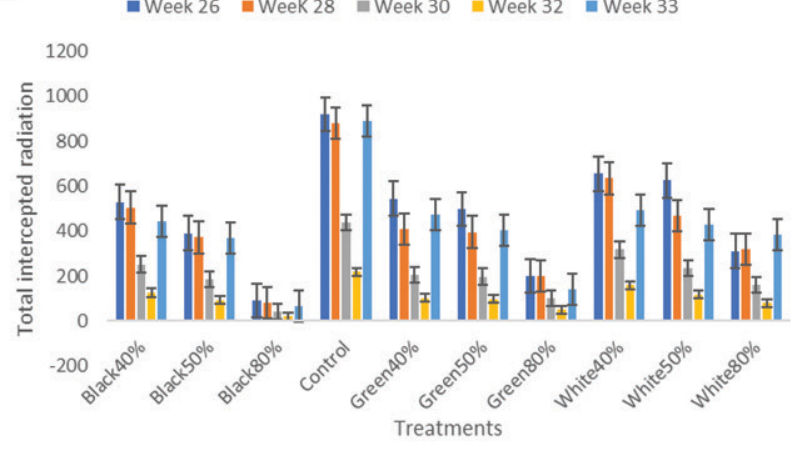

C

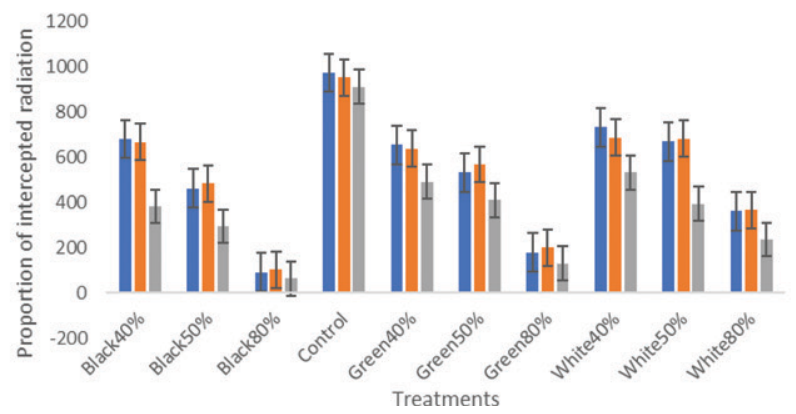

B

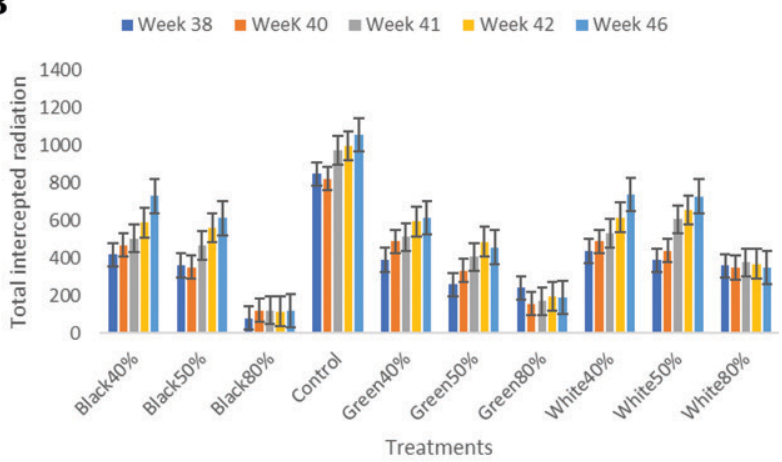

D

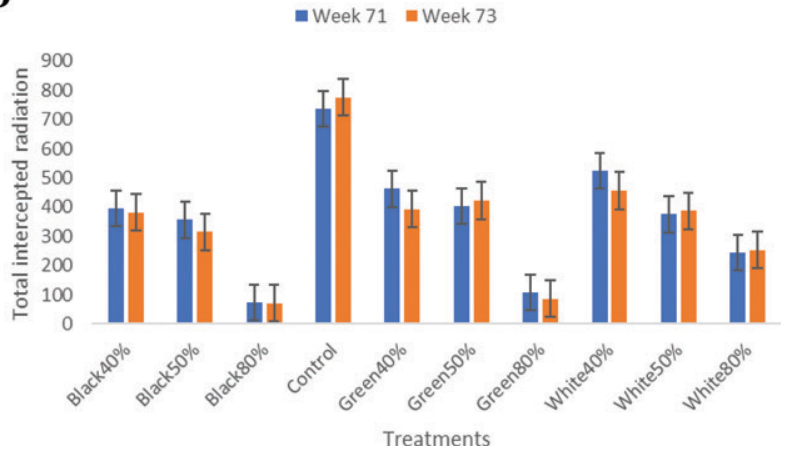

Fig. 5. The effect of treatments on the total radiation in 2018. (A) Winter 2018. (B) Spring 2018. (C) Summer 2018. (D) Autumn 2019. 
A

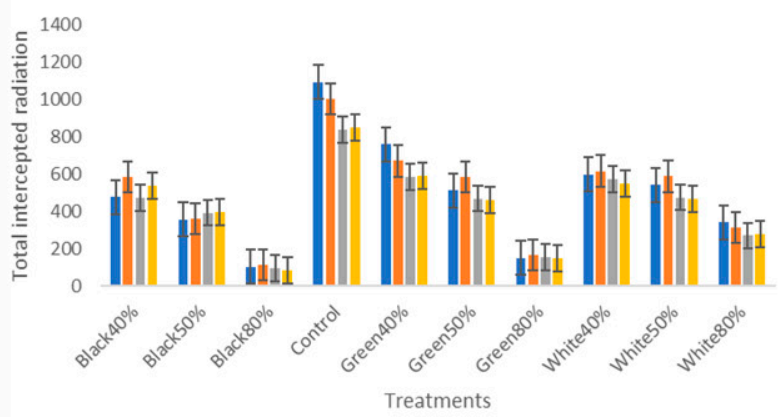

C

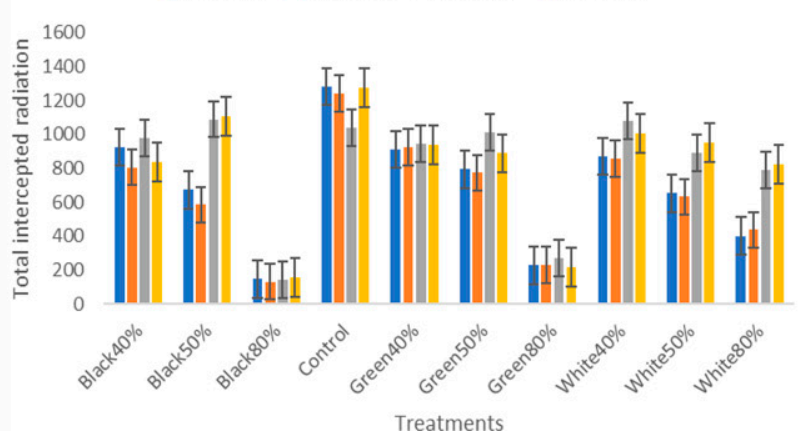

B

-Week 90 WWeeK 92 -Week 95 =Week 97 =Week 98

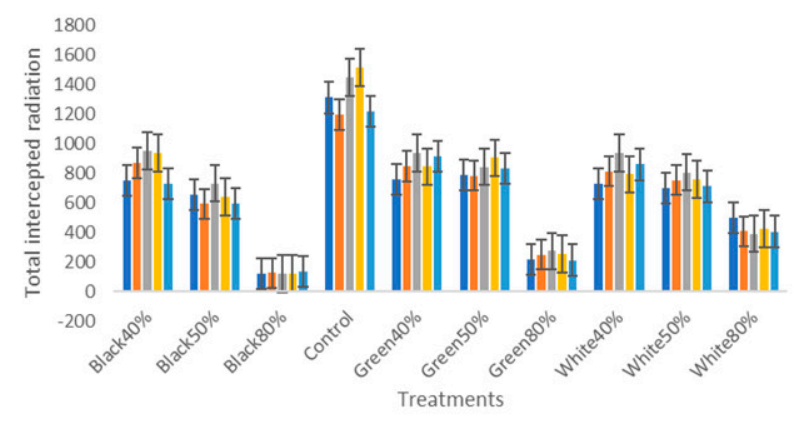

D

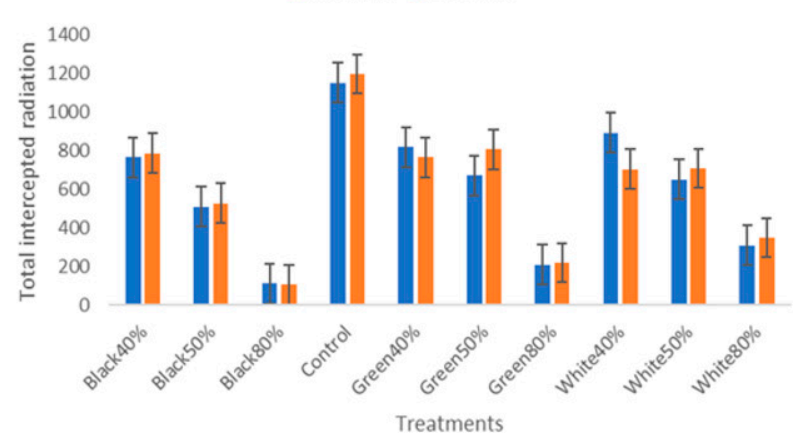

Fig. 6. The effect of treatments on the total radiation in 2019. (A) Winter 2019. (B) Spring 2019. (C) Summer 2019. (D) Autumn 2020.

faster growth and development exhibited in plants exposed to full sunlight compared with those grown under shade (Kumar et al., 2013). More recently, Thakur et al.
(2019) concluded that higher shade level reduced $P A R$, altered light intensities, and affected photosynthetic rate and yield production.
In contrast to our results, Kumar et al. (2013) reported that shaded plants were taller than those exposed to full sunlight, probably due to long internodal lengths
A

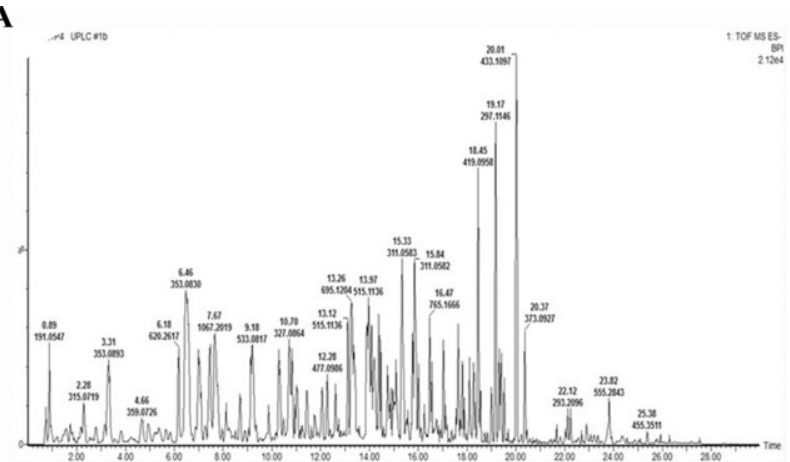

B

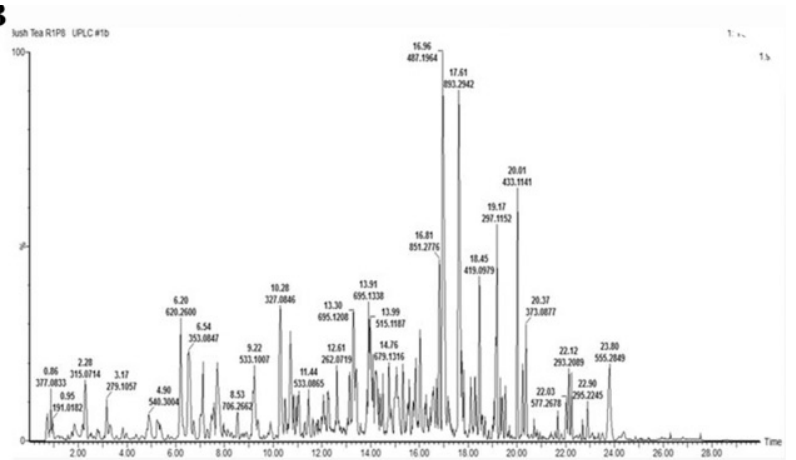

C

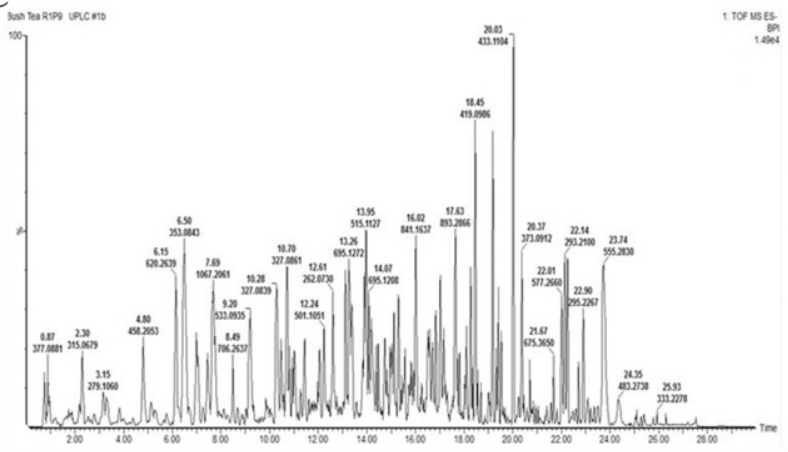

D

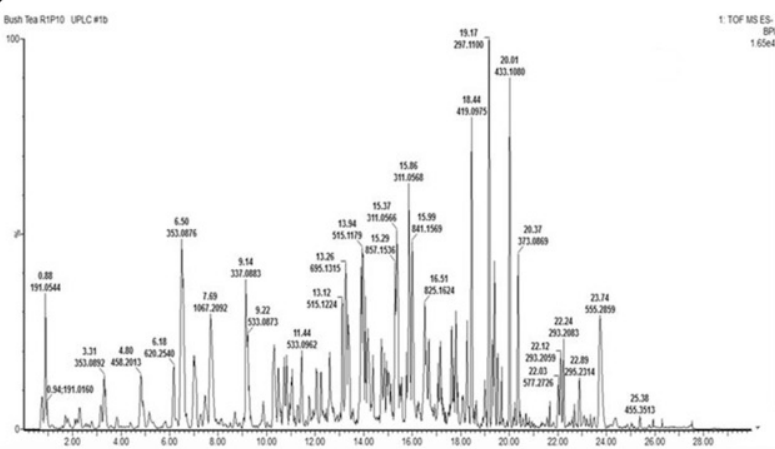

Fig. 7. Representative ultra-high performance liquid chromatography quadrupole time of flight mass spectrometry (UHPLC-QTOF-MS) base peak intensity (BPI) chromatograms showing the separation of secondary metabolites in extracts of bush tea plants exposed to (A) control, (B) black, (C) green, and (D) white, respectively. 


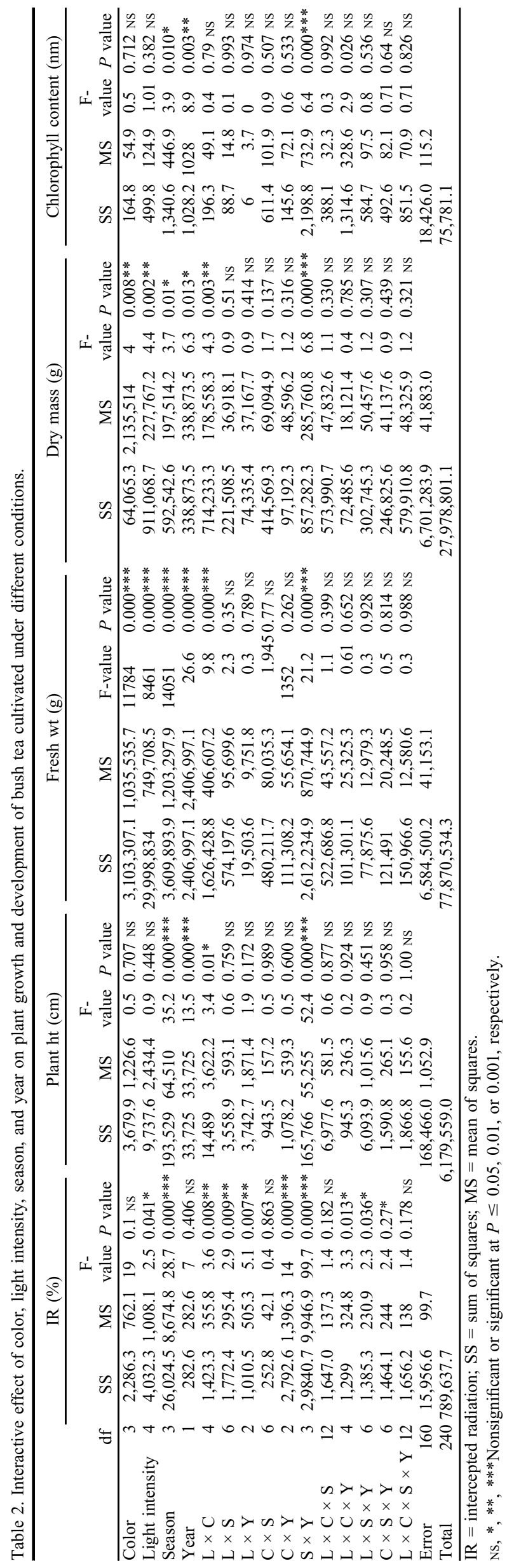

and thinner stems in the plants grown under shade.

The lower fresh and dry mass of bush tea plants in the shaded treatments compared with plants from unshaded plots that we observed in the current study may be attributed partly to a combination of low light and high air temperature, which likely reduced available stored energy rapidly (Svenson, 2002). Similarly, Gregoriou et al. (2007) and Wei et al. (2005) reported that growth and productivity of plants were usually inhibited by lower light intensities through imbalances in gaseous exchange. In contrast, Barua and Gogoi (1979) reported that the yield in tea, especially tea shoots, subjected to light intensity less than $35 \%$ was higher than in tea plants that were exposed to direct full sunlight, which may suggest that unsuitable light intensities were usually capable of causing damage to the plant's photosynthetic system by interfering with photosynthesis and development (Szymborska-Sandhu et al., 2020). Clearly, the effect of light intensity on growth, development, and yield varies greatly and may need further investigation.

The effect of season on plant growth and development. Bush tea plant growth parameters (intercepted radiation, plant height, fresh weight, dry weight, and chlorophyll content) varied with seasons (Table 1). On average, the proportion of intercepted radiation (\%) was higher in summer $(64.6 \%)$ compared with winter $(58.7 \%)$, autumn $(54.9 \%)$, and spring $(36.7 \%)$ (Table 1$)$, perhaps partly due to the larger canopy size that was exhibited in summer. Similarly, fresh biomass was higher in summer (636 g/plant) compared with the rest of the seasons (343.6-550.1 g/plant) (Table 1). For plant height in contrast, the seasons were ranked as follows: autumn $>$ summer $>$ winter $>$ spring (Table 1 ). The higher biomass accumulation in summer was associated with the greater proportion of intercepted radiation recorded in summer. The amount of solar radiation received during the cropping season influences plant growth, development, and yield (Challa and Bakker, 1999; Cockshull et al., 1992). Bush tea yield drops significantly under cloudy conditions, with heavy and continuous rainfall, just like it does when the weather is hot, dry, and sunny.

In contrast to our findings, CTIFL (1995) reported that plant growth and yield was restricted during the summer season because of the effects of higher summer temperatures on photosynthesis and respiration.

Chlorophyll content. There was a significant seasonal variation in chlorophyll content, with the highest recorded in winter $(17.1 \mathrm{~nm})$ and lowest in summer $(11.4 \mathrm{~nm})$ (Table 1). The results are in line with those of MacAlister et al. (2020), who reported that chlorophyll content was higher in winter compared with the summer season.

Interactive effect of color, light intensity, season, and year on plant growth and development of bush tea cultivated under different conditions. There are no distinct research findings that have been reported and discussed on interactive effect of color, light intensity, season, 
A

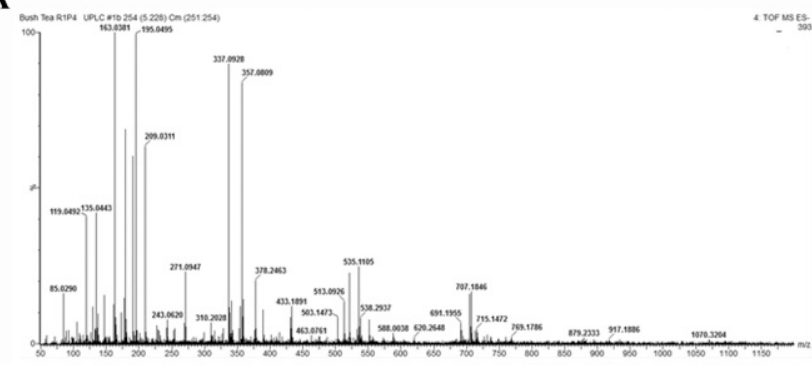

C

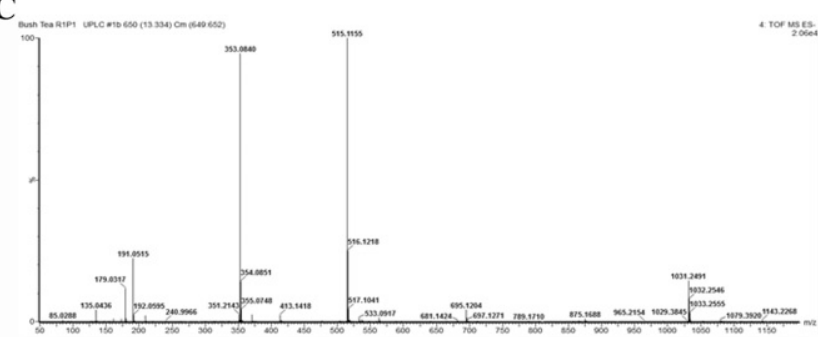

B

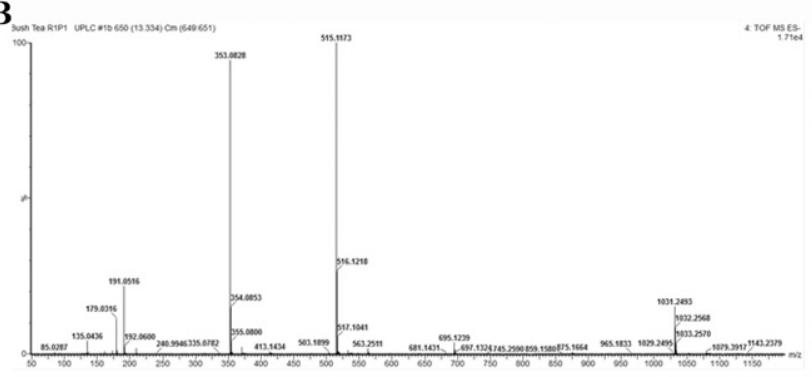

D

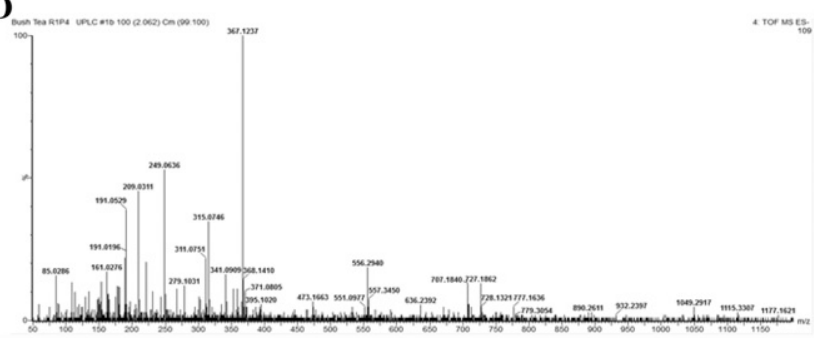

Fig. 8. Representative electrospray ionization (ESI) negative spectrum showing the fragmentation pattern of (A) coumaroylquinic acid, (B) caffeoylquinic acid, (C) dicaffeoylquinic acid, and (D) tricaffeoylquinic acid.

and year on plant growth and development of bush tea cultivated under different conditions.

The interaction between light intensity and color of shade net affected the proportion of intercepted radiation $(P \leq 0.01)$, plant height $(P \leq 0.05)$, and fresh weight and dry mass $(P \leq 0.001)$, but not chlorophyll content (Table 2). In contrast, the interactive effect of light intensity and season as well as light intensity, shade net color, season, and year was only significant on the proportion of intercepted radiation, and the 3-way interaction of light intensity, color of shade net, and season did not affect any plant growth parameter (Table 2).

Identification of CGA in bush tea plants exposed to different shade nets and light intensities. The results revealed that there was greater production of CGAs, viz: caffeoylquinic acid, coumaroylquinic acid, dicaffeoylquinic acid, and tricaffeoylquinic acids (tri-CQAs) in plants that were exposed to white shade net at $80 \%$ level compared with plants that were exposed to full sunlight (Table 3, Fig. 7). LCMS analysis was conducted on the leaf extracts of bush tea grown under different conditions. Only four major CGAs yielded under negative ionization and all fragmentation patterns were generated after negative ionization. $\mathrm{MS}^{2}$ spectra (Fig. 8), achieved through collision-induced dissociation-based approaches, was found to be sufficient for characterization of these molecules.

Different shade nets and light treatments led to differential regulation of secondary metabolite production in bush tea, observed by presence and absence of certain metabolites (Table 3). Dicaffeoylquinic acids were identified equally in all treatments. More peaks of coumaroylquinic acids were detected in the combination of white shade nets and $80 \%$ light intensity compared with the other treatments. Tri-CQAs were detected only in the unshaded control and white shade net at both $50 \%$ and $80 \%$ light intensity. These CGAs are responsive toward light, as their accumulation is subjected to light exposure. CGAs enable plants to adapt in environments with high light intensity by absorbing excess light. Our findings are consistent with earlier observations that secondary metabolite accumulation is affected by plant species, different plant organs, and environmental conditions to which plants are exposed (Hanudin et al., 2012). These findings may be because accumulation of CGAs is related to light intensities. The results contradict those of Karimi et al. (2013), who reported that three different varieties of Labisia pumila Benth exposed to high light intensities results in an enhancement in phenolic compounds such as gallic acid, caffeic acid and flavonoid compounds, which include quecetin, rutin myricetin, kaempferol, and naringin.

Characterization of monoacyl caffeoylquinic acids. Four peaks corresponding to a molecular formula of $\mathrm{C}_{16} \mathrm{H}_{18} \mathrm{O}_{9}$ with precursor ion $[\mathrm{M}-\mathrm{H}]^{-}$at $m / z 353(\mathbf{1 - 4})$ were detected in the chromatogram of all treatments of bush tea extracts. Two peaks ( $\mathbf{1}$ and $\mathbf{4}$ ) were detected as isomers of 3-CQA due to the presence of a peak with the product ions at $\mathrm{m} / \mathrm{z} 191$ and $\mathrm{m} / \mathrm{z}$ 179 at $50 \%$ base peak (Fig. 8B). Similarly, a peak with the product ion at $\mathrm{m} / \mathrm{z} 173$ was identified as 4-CQA (2). A peak with a single product at $\mathrm{m} / \mathrm{z} 191$ was identified as 5CQA (3).

Characterization of p-coumaroylquinic acid. Five peaks with precursor ions at $m / z 337$ (5-9), suggesting a molecular formula of $\mathrm{C}_{16} \mathrm{H}_{18} \mathrm{O}_{8}$, were detected on all treatments of bush tea extracts. These molecules were identified as para-Coumaroylquinic acids ( $p$ CoQA) based on accurate mass and accompanying fragmentation patterns $\left(\mathrm{MS}^{2}\right)$ patterns. Two peaks (5 and 6) were identified as isomers of 5pCoQA due to the presence of the product ion at $\mathrm{m} / z 191$ with additional peaks at $\mathrm{m} / \mathrm{z} 161$, and $m / z$ 135. Another two peaks (7 and 8) with product ions of $\mathrm{m} / \mathrm{z} 163, \mathrm{~m} / \mathrm{z} 179$, and $\mathrm{m} / \mathrm{z} 191$ were identified as 3-PCoQA (Fig. 8A). The presence of product ions at $m / z 173$ allowed the annotation of molecule (9) as 4-pCQA and it was only identified in white shade nets at both $50 \%$ and $80 \%$ light intensities.

Characterization of di-caffeoylglucosides. Three compounds with a precursor ion $[\mathrm{M}-\mathrm{H}]^{-}$at $m / z 515$ were identified as dicaffeoylquinic acid (10-12) in all the treatments used in the study. A peak with product ions at $\mathrm{m} / \mathrm{z} 353, \mathrm{~m} / \mathrm{z} 173, \mathrm{~m} / \mathrm{z} \mathrm{191}$, and $\mathrm{m} / \mathrm{z} 135$ (Fig. 8C) was identified as 3,4-diCQA (10). In addition, a peak with product ions at $\mathrm{m} / \mathrm{z}$ $353, \mathrm{~m} / \mathrm{z} 173, \mathrm{~m} / \mathrm{z} \mathrm{191}$, and $\mathrm{m} / \mathrm{z} 135$ was identified as 3,5-diCQA (11). Similarly, a peak with fragment ion at $\mathrm{m} / \mathrm{z} 353, \mathrm{~m} / \mathrm{z} 173$, $\mathrm{m} / \mathrm{z} 179$, and $\mathrm{m} / \mathrm{z} 135$ was identified as 4,5 diCQA (12) at $\mathrm{MS}^{2}$. These results concur with previous findings (Clifford et al., 2005; Masike et al., 2018) that elution order of diCQA regio-isomers on a reverse-phase column was expected to be 3,4-di-CQA, 3,5-diCQA, followed by 4,5-di-CQA.

Characterization of tri-CQAs. Compound (13) was annotated as 1,3,5-tri-CQA with the product ion of $\mathrm{m} / \mathrm{z} 515, \mathrm{~m} / \mathrm{z} 353, \mathrm{~m} / \mathrm{z} 179$, and $\mathrm{m} / \mathrm{z} 173$, corresponding to the molecular formula of $\mathrm{C}_{34} \mathrm{H}_{30} \mathrm{O}_{15}$, and it was detected in unshaded control, as well as white shade net plots at both $50 \%$ and $80 \%$ light intensities (Fig. 8D).

\section{Conclusions and Recommendations}

The study revealed that bush tea plants grow best when they are exposed to full sunlight, followed by white shade net and black shade net. Bush tea grown under full sunlight improved plant growth and development and, thus, tended to produce taller plants, as well as higher fresh and dry mass. The horticultural practices of using white $(80 \%)$ shading 


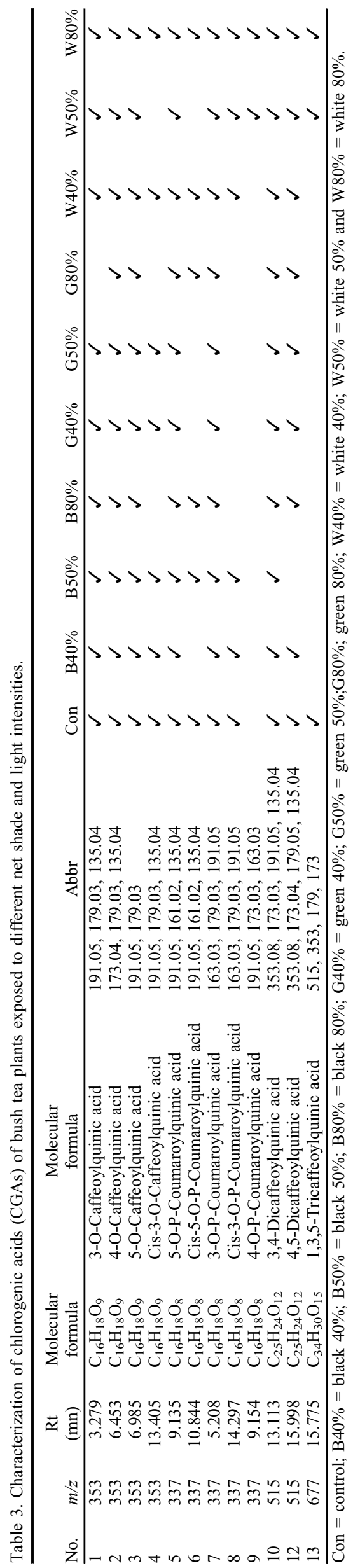

led to greater accumulation of chlorogenic acid as compared with the plants exposed to full sunlight. Therefore, a combination of white shade net and $80 \%$ light intensity may be the best microclimatic tools to enhance CGAs in bush tea production. However, we recommend further studies to investigate the response of bush tea extracts exposed to different colors of the ultraviolet light.

\section{Literature Cited}

Anwar, M.R., B.A. McKenzie, and G.D. Hill 2003. The effect of irrigation and sowing date on crop yield and yield components of Kabuli chickpea (Cicer arietinum L.) in a cool-temperate sub humid climate. J. Agr. 141:259-271, https://doi.org/10.1017/S0021859603003617.

Bandara, S.N. 2012. Agronomy of irrigated tea in low elevation growing areas of Sri Lanka. Univ. Adelaide School Agr., Food Wine, Adelaide, Australia, PhD Diss.

Barua, D.N. and B.N. Gogoi. 1979. Effects of shade removal. Two and a Bud. 26:40-42.

Bell, G.E., T.K. Danneberger, and M.J. McMahon. 2000. Spectral irradiance available for turfgrass growth in sun and shade. Crop Sci. 40 189-195, https://doi.org/10.2135/cropsci2000. 401189x.

Challa, H. and M.J. Bakker. 1999. Potential production within the greenhouse environment, p. 333-348. In: G. Stanhill and Z.H. Enoch (eds.). Ecosystems in the world: Vol. 20 Chapter 15: Greenhouse Ecosystems. Elsevier, Amsterdam, The Netherlands

Clifford, M.N., S. Knight, and N. Kuhnert. 2005. Discriminating between the six isomers of dicaffeoylquinic acid by LC-MSn. J. Agr. Food Chem. 53:3821-3832, https://doi.org/ 10.1021/jf050046h.

Cockshull, K.E., C.J. Graves, and C.R. Cave. 1992. The influence of shading on yield of glasshouse tomatoes. J. Hort. Sci. 67:11-24, https://doi.org/10.1080/ 00221589.1992 .11516215

CTIFL, Centre Technique Interprofessionel des Fruits et des Legumes. 1995. Maitrise de la conduite climatique. Paris. CTIFL, 127.

de Beer, D., E. Joubert, C.J. Malherbe, and D.J. Brand. 2011. Use of counter current chromatography during isolation of 6-hydroxyluteolin-7-O-B-glucoside, a major antioxidant of Athrixia phylicoides. J. Chromatography 1218 6179-6186, https://doi.org/10.1016/j.chroma. 2010.12.096

Fouché, G., E. Khorombi, N. Kolesnikova, V.J. Maharaj, R. Nthambeleni, and M. Van der Merwe. 2006. Investigation of South African plants for anticancer properties. Pharmacologyonline 3:494-500.

Gregoriou, K., K. Pontikis, and S. Vemmos. 2007. Effects of reduced irradiance on leaf morphology, photosynthetic capacity, and fruit yield in olive (Olea europaea L.). Photosynthetica 45:172-181, https://doi.org/10.1007/ s11099-007-0029-x.

Hanlon, E.A., J.S. Gonzales, and J.M. Bartos. 1994. IFAS extension soil testing laboratory chemical procedures and training manual (Circular 812). Fla. Coop. Ext. Serv. Inst Food and Agri. Sci., Univ. of Fla.

Hanudin, E., H. Wismarini, T. Hertiani, and B. Hendro Sunarminto. 2012. Effect of shading, nitrogen and magnesium fertilizer on phyllanthin and total flavonoid yield of Phyllanthus niruri in Indonesia soil. J. Med. Plants
Res. 6:4586-4592, https://doi.org/10.5897/ JMPR12.591.

Haukioja, E., V. Ossipov, J. Koricheva, T. Honkanen, S. Larsson, and K. Lempa. 1998. Biosynthetic origin of carbon-based secondary compounds: Cause of variable responses of woody plants to fertilization. Chemoecology 8:133-139, https://doi.org/ 10.1007/s000490050018

Herman, P.P.J., E. Retief, M. Koekemoer, and W.G. Welman. 2000. Seed plants of Southern Africa. O.A. Leister Editions, National Botanical Institute, Pretoria, South Africa.

Hlahla, L.N. 2010. Effect of fermentation temperature and duration on chemical composition of Bush tea (Athrixia phylicoides DC.). Univ. of Limpopo, Turfloop Campus, Mankweng, South Africa, $\mathrm{PhD}$ Diss

Ibrahim, M.H., H.Z.E. Jaafar, A. Rahmat, and Z.A. Rahman. 2011. Effects of nitrogen fertilization on synthesis of primary and secondary metabolites in three varieties of Kacip fatimah (Labisia pumila Blume). Int. J. Mol. Sci. 12:5238-5254, https://doi.org/ 10.3390/ijms 12085238 .

Janendra, W.A., M. Costa, J.A. Mohotti, and M.A. Wijeratne. 2007. Ecophysiology of tea. Braz. J. Plant Physiol. 19:299-332.

Karimi, E., H.Z. Jaafar, A. Ghasemzadeh, and M.H. Ibrahim. 2013. Light intensity effects on production and antioxidant activity of flavonoids and phenolic compounds in leaves, stems and roots of three varieties of Labisia pumila Benth. Aust. J. Crop Sci. 7:1016-1024.

Ku, K.M., J.N. Choi, J.K. Kim, L.G. Yoo, S.J. Lee, Y.S. Hong, and C.H. Lee. 2010. Metabolomics analysis reveals the compositional differences of shade grown tea (Camellia sinensis L.). J. Agr. Food Chem. 58:418-426, https:// doi.org/10.1021/jf902929h.

Kumar, R., S. Sharma, and V. Pathania. 2013. Effect of shading and plant density on growth, yield and oil composition of clary sage (Salvia sclarea L.) in north western Himalaya. J. Essent. Oil Res. 25:23-32, https://doi.org/ 10.1080/10412905.2012.742467.

Kundu, A. and J. Vadassery. 2019. Chlorogenic acidmediated chemical defence of plants against insect herbivores. Plant Biol. 21:185-189, https:// doi.org/10.1111/plb.12947.

Lallemand, L.A., C. Zubieta, S.G. Lee, Y. Wang, S. Acajjaoui, J. Timmins, S. McSweeney, J.M. Jez, J.G. McCarthy, and A.A. McCarthy. 2012. A structural basis for the biosynthesis of the major chlorogenic acids found in coffee. Plant Physiol. 160:249-260, https://doi.org/10.1104/ pp.112.202051.

Lee, D.W., S.F. Oberbauer, B. Krishnapilay, M Mansor, H. Mohamad, and S.K. Yap. 1997. Effects of irradiance and spectral quality on seedling development of two Southeast Asian Hopea species. Oecologi. 110:1-9.

Lehlohonolo, N., I.K. Mariga, W. Ngezimana, and F.N. Mudau. 2013. Bush tea (Athrixia phylicoides dc.) Success stories in South Africa. A review. J. Crop Prod. 2:37-43.

MacAlister, D., A.M. Muasya, O. Crespo, J.B.O. Ogola, S. Maseko, and A.J. Valentine. 2020. Effect of temperature on plant growth and stress tolerant traits in rooibos in the Western Cape South Africa. Scientia Hort. 263:109137, https://doi.org/10.1016/j.scienta.2019.109137.

Makita, C., L. Chimuka, P. Steenkamp, E. Cukrowska, and E. Madala. 2016. Comparative analyses of flavonoid content in Moringa oleifera and Moringa ovalifolia with the aid of UHPLC-qTOFMS fingerprinting. S. Afr. J. Bot. 105:116-122, https:// doi.org/10.1016/j.sajb.2015.12.007. 
Marchese, J.A. and G.M. Figueira. 2005. Use of technologies before and after harvest and good agricultural practices in the production of medicinal and aromatic plants. Rev. Brasil. Planta Med. 7:86-96.

Masike, K., F. Tugizimana, N. Ndlovu, E. Smit, L. du Preez, I. Dubery, and N.E. Madala. 2017. Deciphering the influence of column chemistry and mass spectrometry settings for the analyses of geometrical isomers of L-chicoric acid. J. Chromatogr. B Analyt. Technol. Biomed. Life Sci. 1052:73-81, https://doi.org/ 10.1016/j.jchromb.2017.03.023.

Masike, K., I. Dubery, P. Steenkamp, E. Smit, and E. Madala. 2018. Revising reverse-phase chromatographic behavior for efficient differentiation of both positional and geometrical isomers of dicaffeoylquinic acids. J. Anal. Methods Chem., https://doi.org/10.1155/2018/8694579.

Mavundza, E.J., T.E. Tshikalange, N. Lall, A.A. Hussein, F.N. Mudau, and J.J.M. Meyer. 2010. Antioxidant activity and cytotoxicity effect of flavonoids isolated from Athrixia phylicoides. J. Medicinal Plant Res. 4(23):2584-2587, https://doi.org/10.5897/JMPR10.823.

Mohale, K.C., A.T. Hintsa, M.A. Emanuel, and F.N. Mudau. 2018. Metabolic profiling of cultivated bush tea (Athrixia phylicoides DC.) in response to different pruning types. Scientia Hort. 53:993-998, https://doi.org/ 10.21273/HORTSCI13023-18.

Mokoka, N.N. 2007. Indigenous knowledge of fever tea (Lippia javanica) and effect of shade netting on plant growth, oil yield and compound composition. Univ. of Pretoria, Pretoria, South Africa, PhD Diss.

Morita, A. and M. Tuji. 2002. Nitrate and oxalate contents of tea plants (Camellia sinensis L.) with special reference to types of green tea and effect of shading. J. Soil Sci. Plant Nutr. 48:547-553, https://doi.org/10.1080/00380768.2002.10409237.

Mphangwe, N.I.K. 2012. Lung pruning: A review of practice. Tea Research Foundation of Central Africa (TRFCA) News. 18-23.

Muchow, R.C., T.R. Sinclair, and J.M. Bennett. 1990. Temperature and solar radiation effects on potential maize yields across locations. J. Agron. 82:338-342, https://doi.org/10.2134/ agronj1990.00021962008200020033x.

Mudau, F.N, H.T. Araya, E.S. Du Toit, P. Soundy, and J. Olivier. 2007. Bush tea (Athrixia phylicoides DC.) as an alternative herbal and medicinal plant in southern Africa: Opportunity for commercialization. Med. Aromatic Plant Sci. Biotechnol. 1:74-76.

Mudau, F.N., P. Soundy, E. Du Toit, and J. Olivier. 2006. Variation in polyphenolic content of Athrixia phylicoides (L.) (bush tea) leaves with season and nitrogen application. S. Afr. J. Bot. 72:398-402.

Nchabeleng, L., F.N. Mudau, and I.K. Mariga. 2012. Effects of chemical composition of wild bush tea
(Athrixia phylicoides DC.) growing at locations differing in altitude, climate and edaphic factors. J. Med. Plants Res. 6:1662-1666, https://doi.org/ 10.5897/JMPR11.1453.

Ncube, E.N., M.I. Mhlongo, L.A. Piater, P.A. Steenkamp, I.A. Dubery, and N.E. Madala. 2014. Analyses of chlorogenic acids and related cinnamic acid derivatives from Nicotiana tabacum tissues with the aid of UPLC-QTOF-MS/MS based on the insource collision-induced dissociation method. Chem. Cent. J. 8:1-10.

Nobela, O., R.S. Renslow, D.G. Thomas, S.M. Colby, S. Sitha, P.B. Njobeh, L. du Preez, F. Tugizimana, and N.E. Madala. 2018. Efficient discrimination of natural stereoisomers of chicoric acid, an HIV-1 integrase inhibitor. J. Photochem. Photobiol. B 189:258-266, https:// doi.org/10.1016/j.jphotobiol.2018.10.025.

Rakuambo, Z.J. 2011. Indigenous knowledge of bush tea (Athrixia phylicoides) and effect of fertigation frequency and growing medium on plant growth. Univ. of Pretoria. Pretoria. South Africa, PhD Diss.

Ramabulana, A.T., P. Steenkamp, N. Madala, and I.A. Dubery. 2020. Profiling of chlorogenic acids from Bidens pilosa and differentiation of closely related positional isomers with the aid of UHPLC-QTOF-MS/MS-based in-source collision-induced dissociation. Metabolites 10:178, https://doi.org/10.3390/metabo10050178.

Rao, L.J. and B.N. Mittra. 1998. Growth and yield of peanut as influenced by degree and duration of shading. J. Agron. Crop Sci. 160:260-265, https://doi.org/10.1111/j.1439-037X.1988. tb00327.x.

Roleira, F.M., C.L. Varela, S.C. Costa, and E.J. Tavares-da-Silva. 2018. Phenolic derivatives from medicinal herbs and plant extracts: Anticancer effects and synthetic approaches to modulate biological activity. Stud. Nat. Prod. Chem. 57:115-156, https://doi.org/10.1016/ B978-0-444-64057-4.00004-1.

Soil Classification Working Group. 1991. A Taxonomic System for South Africa. Department of Agricultural Development, Pretoria, South Africa, 257.

Svenson, S.E. 2002. Shady business. Growers should understand how light levels and photosynthesis are linked in crop production. Amer. Nurseryman 19:23-28.

Szymborska-Sandhu, I., J.L. Przybył, E. Pióro-Jabrucka, A. Jedrzejuk, Z. Weglarz, and K. Bączek. 2020. Effect of shading on development, yield and quality of bastard balm herb (Melittis melissophyllum L.). Molecules 25:2142, https://doi. org/10.3390/molecules25092142.

Tadross, M.A., W.J. Gutowski, B.C. Hewitson, C.J. Jack, and M. New. 2006. MM5 simulations of interannual change and the diurnal cycle of southern African regional climate. Theor. Appl. Climatol. 86:63-80.
Taofiq, O., A.M. González-Paramás, M.F. Barreiro, and I.C.F.R. Ferreira. 2017. Hydroxycinnamic acids and their derivatives: Cosmeceutical significance, challenges and future perspectives, a review. Molecules 22:281, https://doi. org/10.3390\%2Fmolecules22020281.

Thakur, M., V. Bhatt, and R. Kumar. 2019. Effect of shade level and mulch type on growth, yield and essential oil composition of damask rose (Rosa damascena Mill.) under mid hill conditions of Western Himalayas. PLoS One (14):e0214672.

Tounekti, T., E. Joubert, I. Hernández, and S. Munné-Bosch. 2013. Improving the polyphenol content of tea. Crit. Rev. Plant Sci. 32:192-215, https://doi.org/10.1080/07352689.2012.747384.

Tshivhandekano, I., K. Ntushelo, W. Ngezimana, T.E. Tshikalange, and F.N. Mudau. 2014 Chemical compositions and antimicrobial activities of Athrixia phylicoides DC. (bush tea), Monsonia burkeana (special tea) and synergistic effects of both combined herbal teas. Asian Pac. J. Trop. Med. 7:S448-S453, https://doi. org/10.1016/S1995-7645(14)60273-X.

Tshivhandekano, I., F.N. Mudau, P. Soundy, and W. Ngezimana. 2013. Effect of cultural practices and environmental conditions on yield and quality of herbal plants: Prospects leading to research on influence of nitrogen fertilization, planting density and eco-physiological parameters on yield and quality of fieldgrown bush tea (Athrixia phylicoides DC.) J. Med. Plants Res. 7:2489-2493, https:// doi.org/10.5897/JMPR2013.4466.

Van Wyk, B.E. and N. Gericke. 2000. People's plants: A guide to useful plants of Southern Africa. 1st edition. Briza publications. 102.

Wang, Y., L. Gao, Y. Shan, Y. Liu, Y. Tian, and T. Xia. 2012. Influence of shade on flavonoid biosynthesis in tea [Camellia sinensis (L.) O. Kuntze]. Scientia Hort. 141:7-16, https://doi org/10.1016/j.scienta.2012.04.013.

Wanyoka, J.K. 1983. Fertilizer on tea: Nitrogen a review. Tea (Nairobi) 4:28-35.

Wei, S.L., W.Q. Wang, X.H. Chen, S.Y. Qin, and X.T. Chen. 2005. Studies on the shade-endurance capacity of Glycyrrhiza uralensis. China J. Chinese Materia Medica 30:100-104.

Yilmaz, G., N. Kandemir, and K. Kinalioglu. 2004. Effects of different pruning intervals on fresh shoot yield and some quality properties of tea (Camellia sinensis L. Kuntze) in Turkey. Pak. J. Biol. Sci. 7:1208-1212, https://doi.org/ 10.3923/pjbs.2004.1208.1212.

Zhang, Q., Y. Shi, L. Ma, X. Yi, and J. Ruan. 2014. Metabolomic analysis using ultra-performance liquid chromatography-quadrupole-time of flight mass spectrometry (UPLC-Q-TOF MS) uncovers the effects of light intensity and temperature under shading treatments on the metabolites in tea. PLoS One (9):112572, https://doi.org/10. 1371/journal.pone.0112572. 